\title{
CONFERENCE
}

\section{British Dental Conference and Exhibition 2006 Photographic Report}

The 2006 British Dental Conference and Exhibition, held in Birmingham from 18-20 May, was the BDA's biggest conference yet - a total of 3,622 delegates and exhibitors gathered at the International Convention Centre for three days of seminars and lectures and a packed exhibition hall. The overall theme of the conference was 'Making it work together', reflecting dentistry's current environment of change.

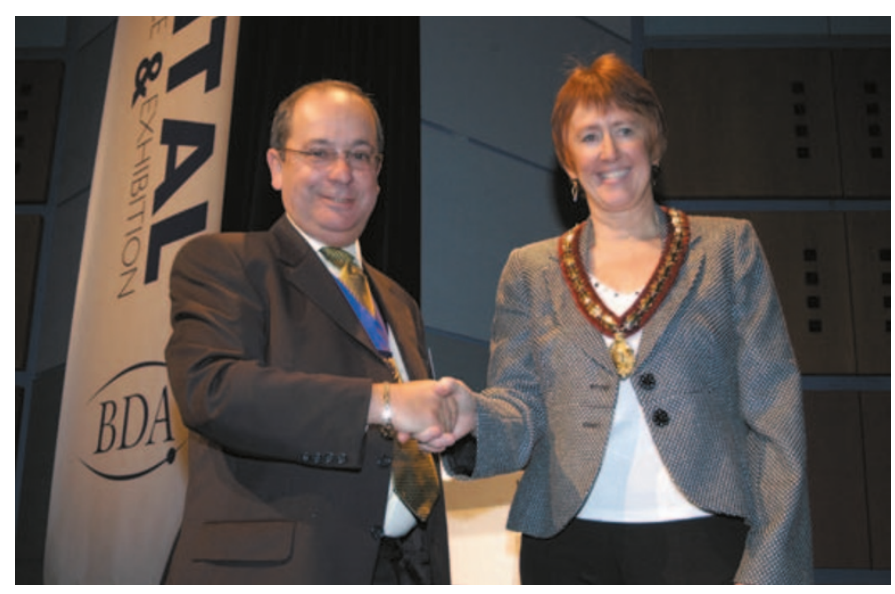

Trevor Mann, Chairman of the Representative Body, congratulates Sue Greening the incoming President and only the third woman in he BDA's history to hold the office

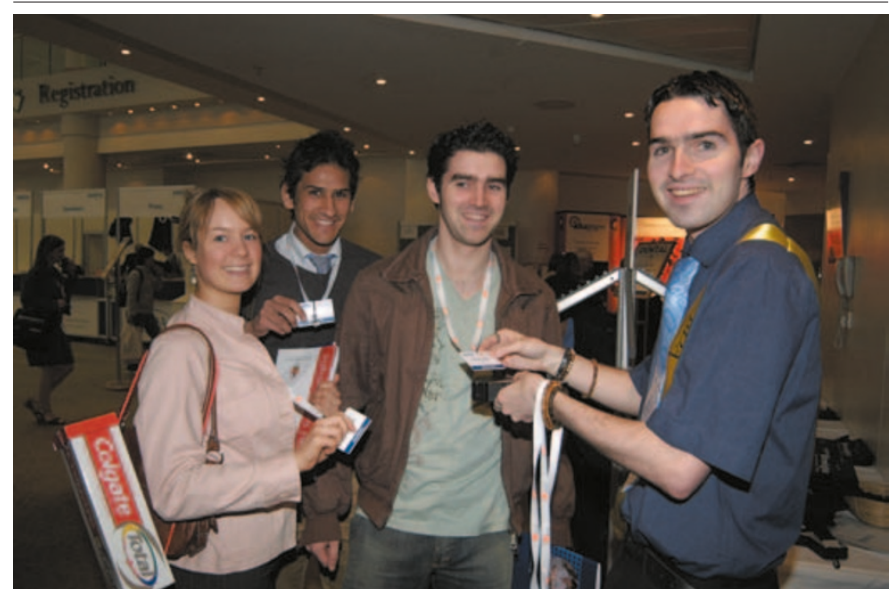

Happy delegates queue up to enter

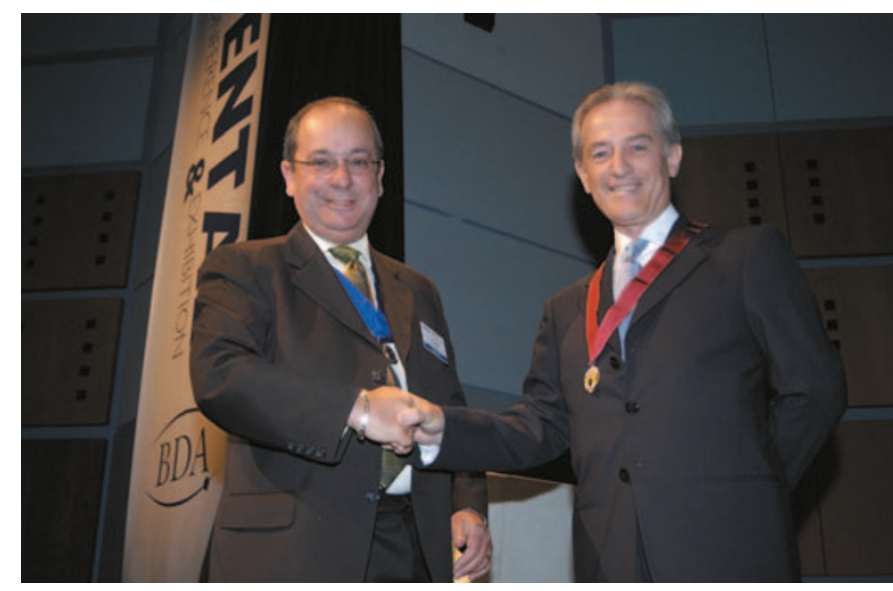

Trevor congratulates immediete past-President John Craig on a successful year in office

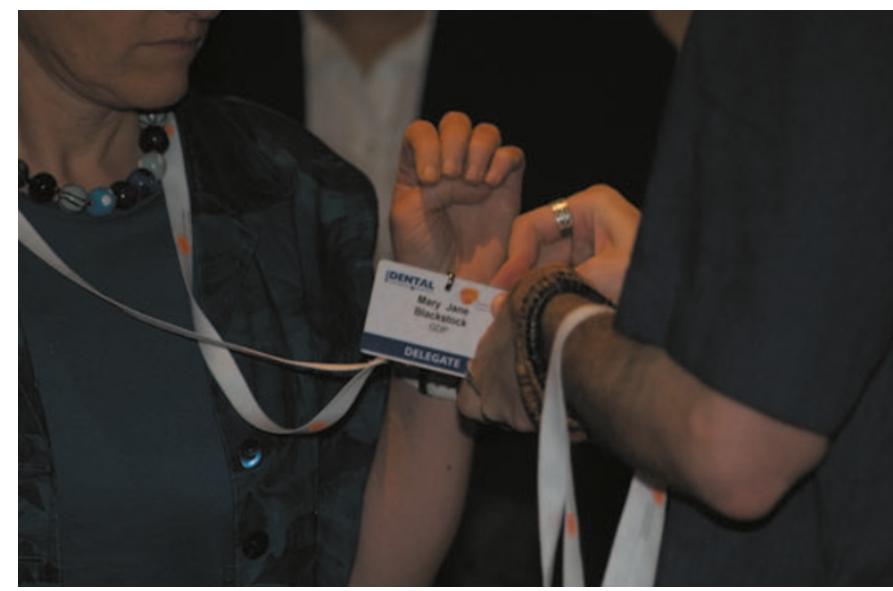

Getting swiped for CPD 


\section{CONFERENCE}
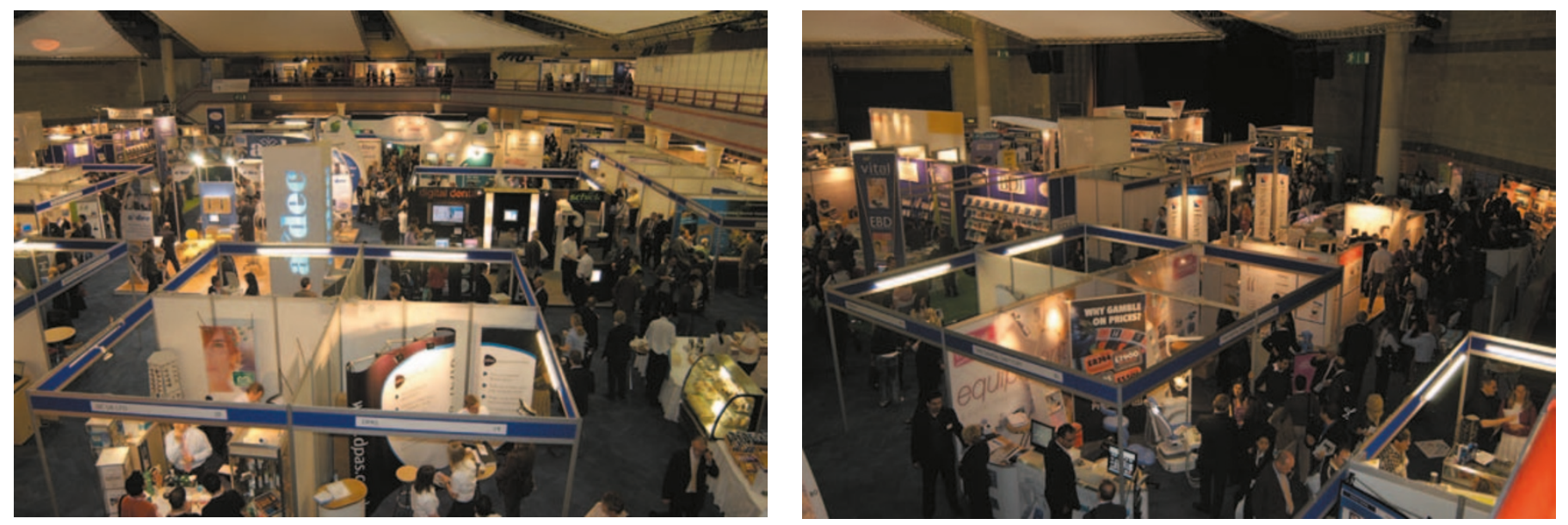

The exhibition area was large, sold out and well attended

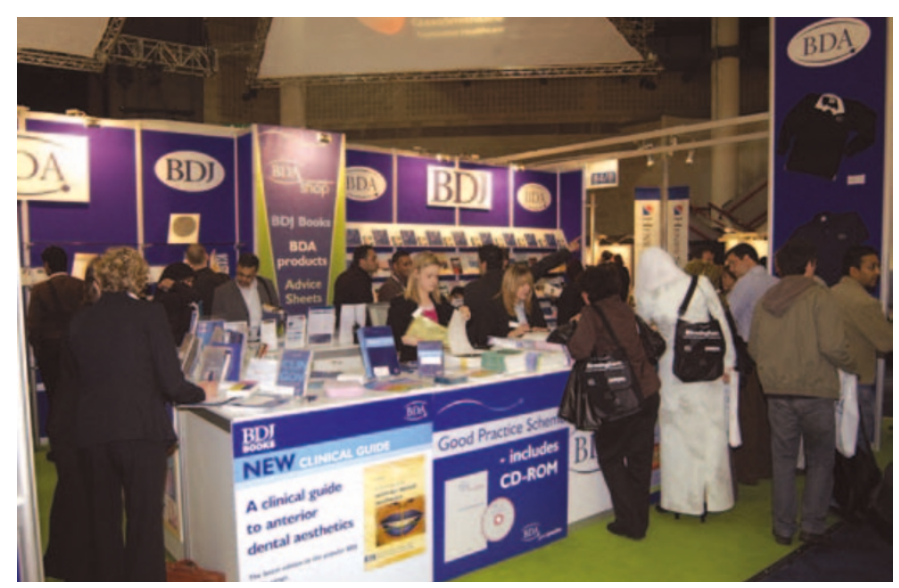

Busy times on the BDA stand, where new members joined and much merchandise was sold

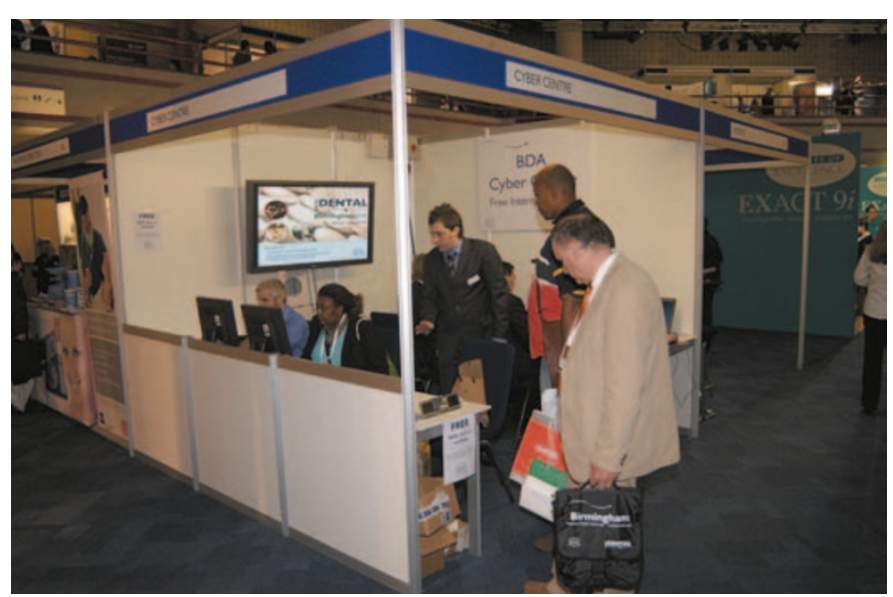

The BDA's free internet zone proved very popular throughout the conference

BRITISH DENTAL JOURNAL VOLUME 200 NO. 11 JUN 102006

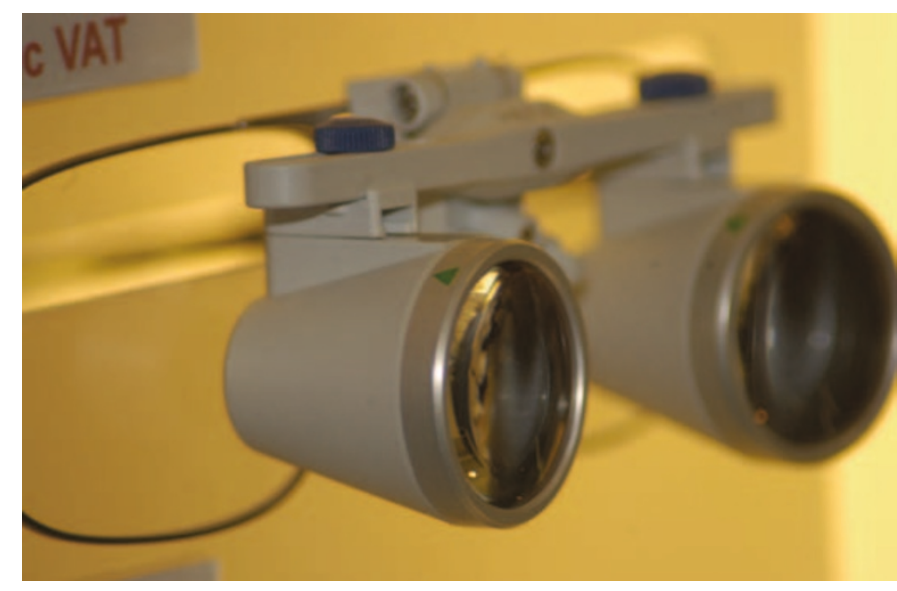

Someone had their eyes on some new kit!

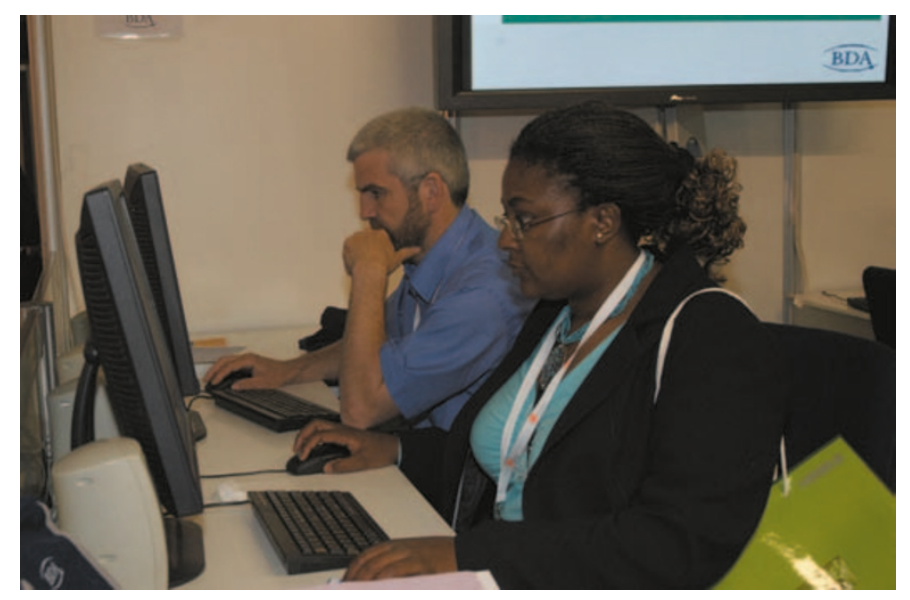

Surfing central Birmingham style 


\section{CONFERENCE}
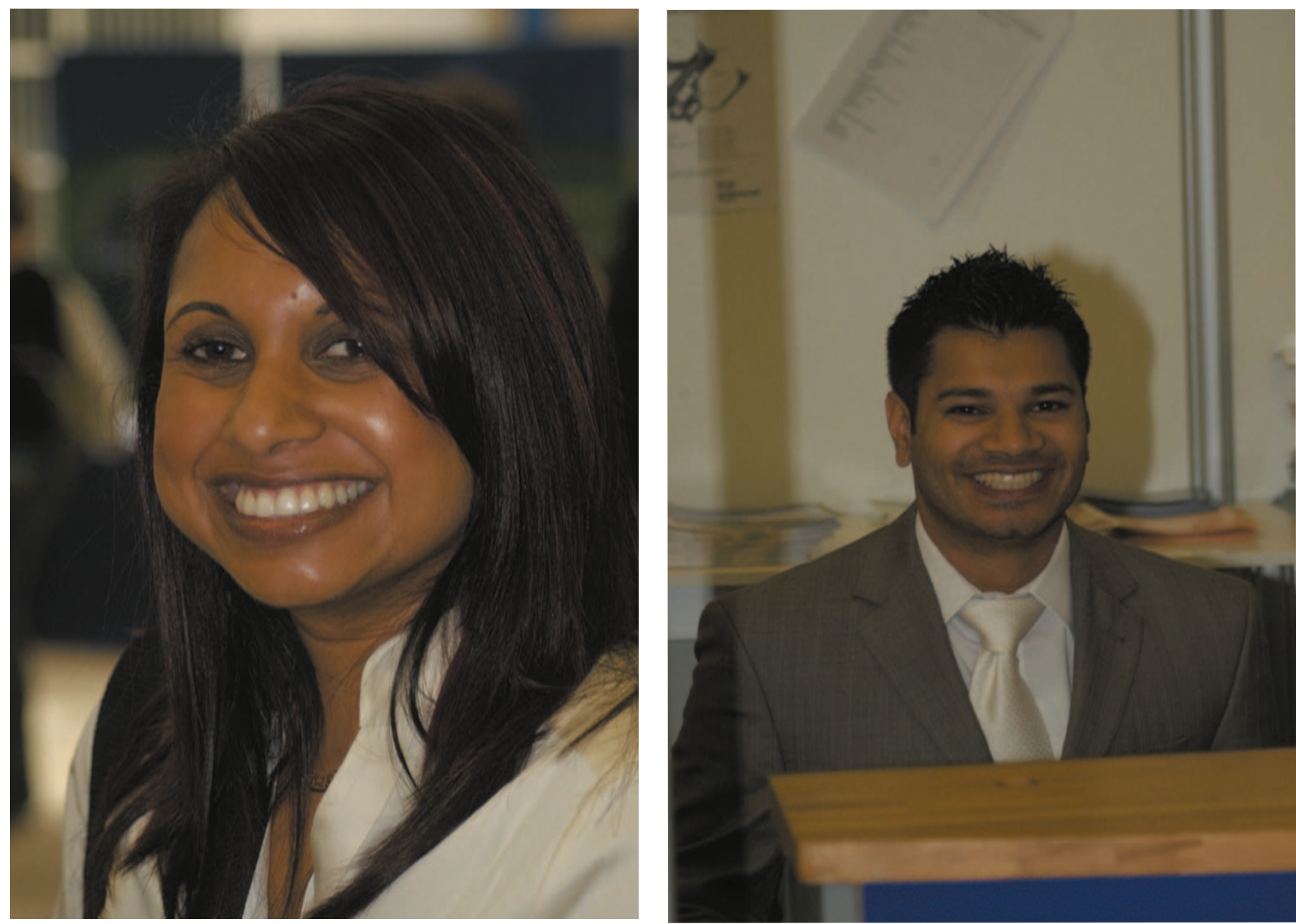

Happy smiles were a feature of the Conference, while William Liebenberg (left) explained to delegates in his 'sold out' plenary-session how best to create and preserve them

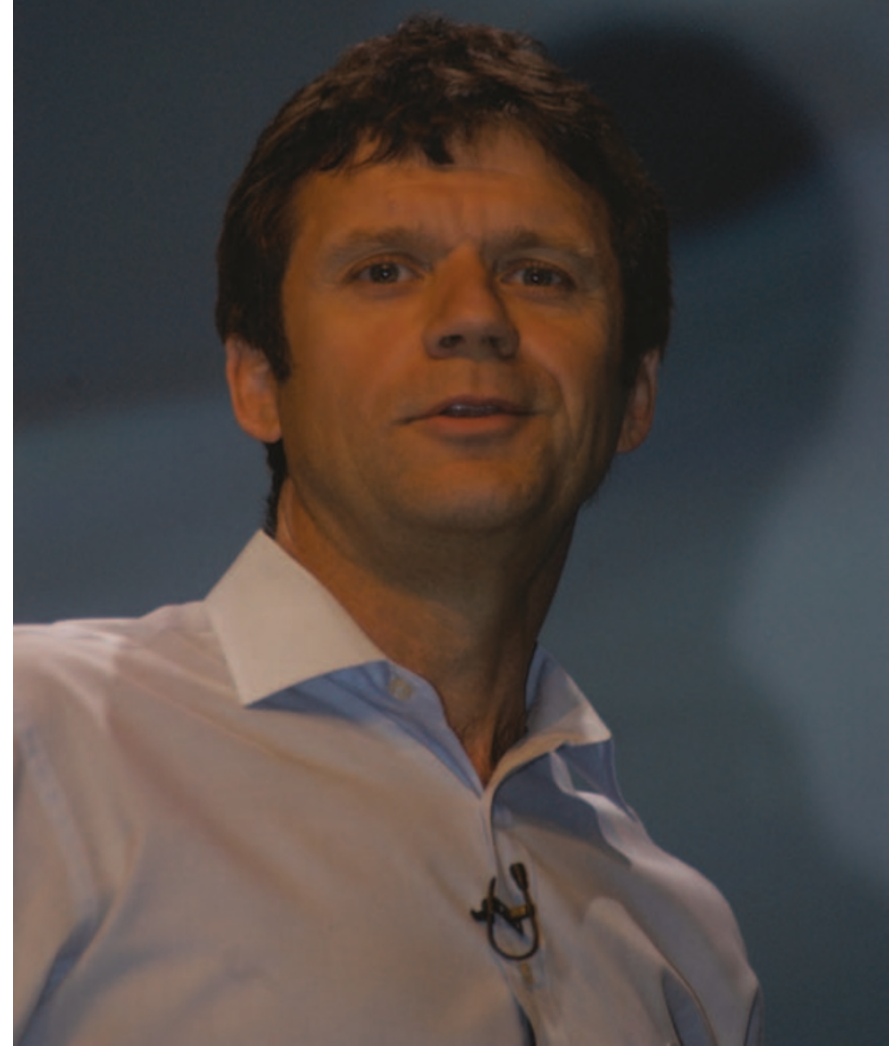



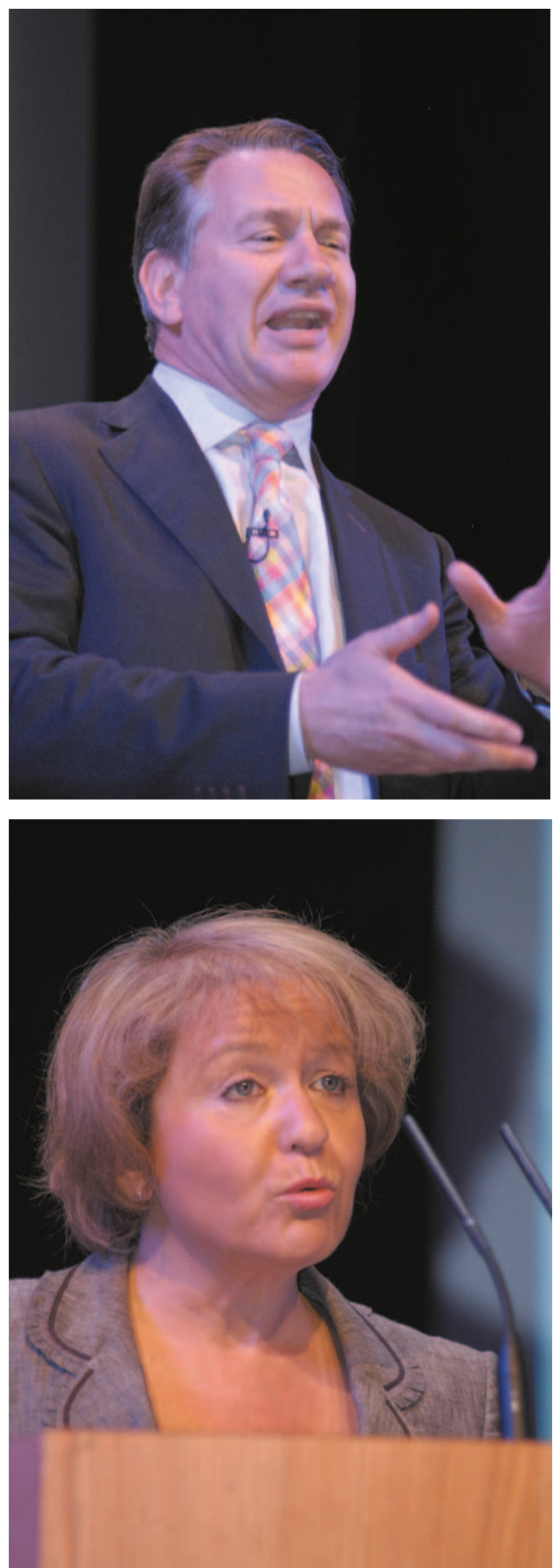

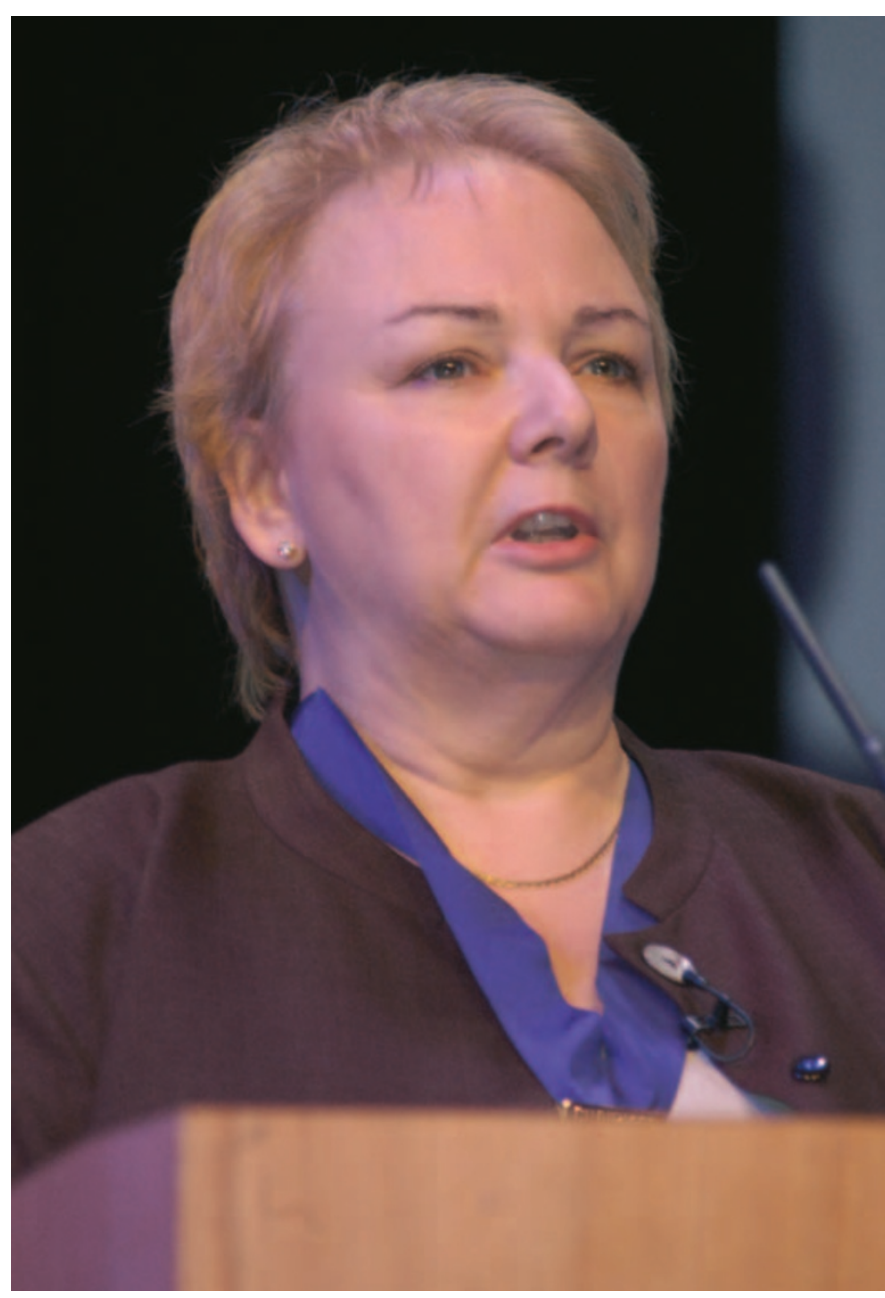

Michael Portillo's keynote speech opened the Conference with a dash of humour, charm and a goodly measure of thoughtful advice (above left)

BDA Executive Board chair Susie Sanderson told delegates to develop existing networks and create strong teams (above)

Dentistry Minister Rosie Winterton was left in no doubt about dentists' grave concerns over the new NHS contract (left) 